"La promoción de ventas en el diario impreso: debilidades y oportunidades. Comparativa de cuatro cabeceras de Málaga y Alicante".

AUTORAS: Dra. Gloria SANTIAGO MÉNDEZ. Universidad de Sevilla

Dra. Alicia de LARA GONZÁLEZ. Universidad Miguel Hernández de Elche

\title{
La promoción de ventas en el diario impreso: debilidades y oportunidades. Comparativa de cuatro cabeceras de Málaga y Alicante
}

The Sales Promotion in the Newspaper: Weaknesses and Opportunities. Compared Study of Four Daily of Malaga and Alicante 


\title{
RESUMEN
}

Las promociones de ventas que acompañan a las publicaciones se han convertido en un elemento fundamental en la estrategia de difusión de la mayoría de diarios. Sin embargo, en los últimos años, debido a la saturación entre los productos que compiten en el kiosco y a la falta de estrategia -entre otros factores relacionados con la crisis de los medios tradicionales- la herramienta de promoción de ventas empieza a mostrar signos de insuficiencia para motivar la difusión. Para concluir hasta qué punto las promociones de ventas puestas en marcha por los departamentos de marketing de las cabeceras siguen una línea estratégica acertada o ineficaz, en la presente investigación se analizan las promociones de ventas servidas durante el año 2010 por cuatro cabeceras locales alicantinas y malagueñas. La prensa provincial ofrece ciertos matices de interés sobre el uso de la estrategia de promoción de ventas, al poder acercar al lector productos propios de la idiosincrasia local común a la propia publicación.

El estudio se completa con las opiniones de los directores de marketing de las cabeceras para ofrecer una visión global de la herramienta, tanto sus características reales como lo que de ella se espera. Asimismo, se ofrece una radiografía de la utilización de esta técnica por otros sectores ajenos al mundo periodístico, que posibilita la comparativa de las acciones. Esta metodología multidisciplinar nos permite apuntar ciertos fallos que predominan en las promociones de ventas que acompañan al diario local y ofrecer propuestas de actuación que revitalicen la estrategia.

Palabras clave: publicidad, prensa, promoción, marketing

\begin{abstract}
The sales promotion sold together with the newspaper have become a fundamental element of the sales strategy of most journals. However, in recent years, due to saturation between products in the newsstand, and the lack of strategy after its launch, among other factors related to the crisis of traditional media, the tool begins to show signs of failure to motivate sales. To conclude the extent to which sales promotion launched by the marketing departments of the headers are a strategic rightly or ineffective, this research analyzes the developments served in 2010 by four local headers of Alicante and Malaga. The provincial press offers some variation of interest concerning the use of sales promotion strategy to bring the reader closer to the products of the local idiosyncrasies common to the publication itself.

The study is complemented with opinions of marketing managers headers to provide an overview of the tool features both real and what is expected of it. While it provides a snapshot of the use of this technique for other sectors outside the journalistic world that allows the comparison of the shares. This multidisciplinary approach allows us to point out certain shortcomings that prevail in the implementation of sales promotion that accompany the local daily and offer proposals for action to revitalize the strategy.
\end{abstract}

Key words: advertising, press, promotion, marketing 


\section{Introducción e hipótesis}

Pareos, baterías de cocina, sacacorchos, camisetas del equipo de fútbol local, collares, libros de misterio, colecciones de música, pendientes indígenas... Los artículos que se ofertan o regalan junto al periódico son de diferente índole y constituyen un elemento fundamental en la estrategia de venta de diarios y revistas. Sin embargo, la saturación y cierta falta de estrategia a la hora de planificar las promociones de ventas, sumadas a otros factores relacionados con la crisis de los medios tradicionales, provocan que esta herramienta propia del marketing editorial resulte insuficiente para frenar la caída de las ventas'.

La hipótesis de partida del presente trabajo se centra en determinar hasta qué punto las promociones de ventas puestas en marcha por los departamentos de marketing de las cabeceras siguen una línea estratégica acertada. A través del estudio, clasificación y análisis de las promociones de ventas servidas durante el año 2010 por cuatro de las 6 cabeceras locales alicantinas y malagueñas que cuentan con la mayor difusión, se trazan las líneas generales, los aciertos y las debilidades de la estrategia que rodea a la promoción de ventas de un periódico impreso local. Se ha tenido en cuenta la opinión de los directores de marketing de estos cuatro periódicos, con el objetivo de establecer conclusiones prácticas, no alejadas de la realidad empresarial, que estos profesionales han reflejado en las entrevistas personales realizadas. Con el objetivo de determinar los puntos de mejora, el análisis se complementa con el estudio comparado de la estrategia de marketing adoptada por otros productos ajenos al mundo editorial. Los esfuerzos se centran en el diario de proximidad porque se le considera un producto periodístico que cuenta con características, ajenas a la prensa nacional, que le otorgan ciertas ventajas a la hora de sobrevivir en la era digital.

\section{Marketing periodístico}

El mercado de la prensa cuenta con una característica que lo diferencia de cualquier otro sector: ofrece opiniones y tiene capacidad de influir en los consumidores. Posee una dimensión cultural y educativa, un aspecto que obliga a situarlo en una posición diferente a la que ocupan los productos de mero consumo. A la hora de pensar en estrategias de marketing adecuadas, será necesario tener en cuenta todas estas características que convierten a los medios de comunicación en un eslabón importante de la industria cultural. El objetivo de aumentar las ventas ha de caminar en consonancia con esta dimensión cultural de la prensa, que es producto, pero también servicio.

La principal diferencia entre producto y servicio es lo tangible (Lovelock, 1983). El producto es perceptible, se puede tocar, apreciar por los sentidos, mientras que el servicio no. Decimos que la prensa impresa es un 'producto - servicio' porque el contenedor de la información y la opinión (el papel) se considera un producto tangible, fruto del trabajo de elaboración y fabricación de muchas personas. Pero también se considera un servicio por la necesidad social de información fundamental que cubre en el seno de un estado de Derecho.

Pero lo cierto es que el diario es un producto que hay que vender, con independencia de su dimensión especial y el marketing debe utilizarse para ese fin. En palabras de Crespo de Lara: "La empresa de prensa, no es una empresa como las industriales, sino que, además de serlo, es fundamentalmente una empresa política, intelectual y cultural. Tiene por objeto hacer periódicos y venderlos" (1993: 22). Al tratarse de un 'producto - servicio', el marketing no sólo debe ocuparse de criterios económicos, se busca una efectividad también social y cultural, en consonancia con el contexto propio del que se nutre el medio para crear contenidos.

1 El mes de septiembre de 2011 experimentó caídas generalizadas en la difusión de todos los diarios de tirada nacional. La Razón (-24\%), ABC (-14\%) y La Gaceta (-13\%) fueron los más afectados, aunque El País (-2,2\%) y El Mundo (-4\%) también retrocedieron. (OJD, 2011). 
Siguiendo este razonamiento, no resulta lógico aplicar una misma estrategia de marketing promocional en un banco que en un periódico. Antes de lanzar una promoción de ventas es necesario plantearse una serie de interrogantes: si la promoción se lanza de venta al número o través de suscriptores; qué porcentaje de ingresos se pretende obtener con cada opción y cuál es el porcentaje que se tiene previsto alcanzar; en qué zonas se pretende difundir la publicación y cuál es el objetivo principal perseguido.

\section{La técnica de las promociones en el diario impreso}

Aunque no existe unanimidad a la hora de fijar el origen de la técnica de la promoción de ventas en prensa, los estudios (Santana, 2002: 42 y Álvarez, 2006: 55) apuntan a que su inicio tiene lugar en la década de los 50. Concretamente en España, es en los años 80 (López, 2004: 35) cuando se afianza su práctica en el mercado mediático: "El periódico de Catalunya fue el primero en obsequiar a sus lectores con un libro. Después, en pleno verano, regaló toallas de baño. Más tarde, en uno de los aniversarios del rotativo, obsequió con una botella de champán catalán".

En un principio, a diferencia de lo que predomina en la actualidad, "los periódicos comenzaron entregando artículos muy afines al diario; fascículos que iban integrados en el precio de la portada. Una vez agotado el modelo inicial, la prensa arrancó con colecciones de pago, basadas en productos que no pertenecían necesariamente al mercado editorial: juegos de mesa, CDs, DVDs, videocámaras, coches teledirigidos, etc." (Ferrán, 2008:17).

Hoy la estrategia de promoción de ventas está muy consolidada en la prensa impresa española. "La promoción? se ha convertido en el recurso estrella de las estrategias de marketing de periódicos y revistas" (Montero, 2005: 221). Sobre todo si la comparamos con otros países que, por su estrategia de ventas, no muestran una dependencia tan grande hacia esta técnica. "En Estados Unidos sólo el $20 \%$ de revistas se vende en kiosco, mientras que el $80 \%$ restante corresponde a suscripciones" (Montero, 2005: 221). Sorprende que en USA y en otros países como Inglaterra "el uso de la promoción de ventas no tenga tanto éxito, siendo prácticamente nula la política promocional" (Santana, 2002: 325). La diferencia fundamental entre la política de promoción de ventas americana y española es el fuerte arraigo que posee en Estados Unidos la suscripción.

El público acostumbra a recibir en el domicilio la revista o periódico, lo que evita que la publicación tenga que competir en el kiosco con el resto de publicaciones. En España, por el contrario "la venta por suscripción ya no goza de la fervorosa estimación que tuvo en el pasado entre las empresas periodísticas. Hace décadas, en realidad, que comenzó a cuestionarse en España el interés económico de los tradicionales descuentos con que se premiaba al suscriptor" (Rodríguez Iniesta, 2008: 761-786). Esto se traduce en que "en el caso de España, el sistema mayoritariamente utilizado por los lectores para adquirir las publicaciones es la venta al número, preferentemente en kioscos. Y que a la venta al número le sigue, muy de lejos, la venta por suscripción" (Santín, 2009: 51). La técnica de promoción de ventas se ha convertido en una herramienta de uso prácticamente obligatorio para las grandes publicaciones.

A pesar de su relevancia en el terreno del marketing, existen ciertos problemas en torno a la promoción de ventas. Por una parte, problemas que conciernen a la investigación de otras muchas técnicas relacionadas con la publicidad below the line: la falta de un método de comprobación de la eficacia. InfoAdex ${ }^{3}$ no analiza la inversión en esta herramienta de una manera individualizada. Esto imposibilita demostrar con cifras la eficacia de la herramienta. La OJD4 tampoco "se muestra cómo una fuente útil para evaluar los resultados de las promociones"

2 El profesor Montero utiliza el término 'promoción' para referirse a la herramienta concreta de la 'promoción de ventas', acepción por la que se ha optado en la presente investigación para evitar confusiones.

3 Recordamos que InfoAdex actualmente distingue entre los siguientes medios no convencionales: actos de patrocinio, mecenazgo, marketing social y R.S.C, actos de patrocinio deportivo, animación en el punto de venta, anuarios, guías y directorios, buzoneo y folletos, catálogos, ferias y exposiciones, juegos promocionales, mailing personalizado, marketing telefónico, marketing móvil, P.L.V., merchandasing, señalización y rótulos, publicidad de empresas: revistas, boletines, memorias, regalos publicitarios y tarjetas de fidelización.

$4 \quad$ La OJD es la Oficina de Justificación de la Difusión. Se encarga de controlar la tirada y difusión de diferentes medios de comunicación españoles, entre los que se encuentran las publicaciones impresas y los medios de comunicación digitales. 
(Santana, 2002: 333) por diferentes motivos: "que en los últimos años se enlacen unas promociones con otras o que confluyan dos o tres promociones al mismo tiempo, de manera que es imposible ver los resultados individuales con claridad" (Santana, 2002: 333).

Los datos publicados en el Libro Blanco de la prensa diaria (AEDE, 2012) revelan que mientras las promociones de ventas en los diarios generalistas 5 han aumentado casi un $25 \%$ desde 2007, las cabeceras han sufrido una pérdida de ingresos de un $28,7 \%$ (2.125 millones de euros). De la misma manera que la penetración porcentual de las cabeceras ha disminuido, según el EGM 2012, desde un 41,3 a un 36,4. Las cifras ponen de manifiesto que la estrategia de promoción de ventas es incapaz de hacer frente al descenso de ventas y a la pérdida de audiencia.

\subsection{Estado de la cuestión}

No abundan los estudios referentes al ámbito de las promociones en prensa impresa. En el caso de España el proyecto de Ainhoa Ferrán Morgado de la Universidad Abat Oliva CEU, centrado en las promociones gratuitas de dos diarios catalanes (El Periódico de Catalunya y ADN) expone que un escaso porcentaje de los nuevos clientes que adquieren la cabecera por la promoción, se convierten en lectores una vez finalizada. Es decir, que a pesar de que esté tan implantada la cultura de la promoción de ventas, asociada a un tipo de consumidor que se mueve por este tipo de productos complementarios, en realidad, el verdadero objetivo de la técnica (aumentar las ventas) no funciona a largo plazo:

"El kiosco adquiere en la actualidad la estética propia de un bazar al ofrecer junto a la prensa artículos promocionales tan variados como vajillas, enciclopedias, DVDs, insectos disecados, relojes, abanicos, entradas a espectáculos, juegos o utensilios de cocina. La oferta promocional se va distanciando del soporte editorial para adoptar una forma más diversificada y menos próxima al producto informativo, al mismo tiempo que intensifica su estrategia de encadenar varias promociones - principalmente de negocio- y concentrarlas en un mismo día. El riesgo del periódico a perder la credibilidad del lector por transmitir, con esta práctica, una imagen excesivamente mercantilista conduce a cuestionarse acerca de la rentabilidad de su esfuerzo promocional" (Ferrán, 2008: 8).

Entre las conclusiones sobre la técnica a las que llega el análisis de Martínez, Juanatey y Orosa (2007: 7) destaca la que apunta que "si bien la fidelidad de los consumidores puede verse alterada, el criterio de los mismos a la hora de decantarse por una $u$ otra cabecera no depende únicamente de la existencia o no de promociones de ventas, sino de otras variables como pueden ser la calidad de éstas". Los autores diferencian entre tres perfiles de compradores/lectores:

1. Los clientes infieles a las cabeceras, quienes no se inclinan por ninguna en concreto, sino que pueden comprar cualquier otro periódico en el caso de que la promoción de ventas ofertada satisfaga sus intereses.

2. Los clientes fieles a las cabeceras, quienes si se sienten atraídos por la promoción de ventas que lanza el competidor, la compran junto a su diario habitual.

3. Los clientes fieles a una cabecera, pero insatisfechos con la misma. Estos son un objetivo prioritario para cualquier campaña de promoción de ventas que prime la fidelización. Y es posible añadir una cuarta clasificación (no reconocida entre las anteriores que se circunscriben a los lectores/compradores de periódicos usuales): los clientes que no son habituales compradores de periódicos, pero que pueden sentirse atraídos por una promoción de ventas (bien al acercarse al punto de venta o al verla anunciada en los medios de comunicación).

De nuevo centrada en la prensa de Cataluña, destaca la tesis doctoral realizada por Santana López (2002), donde se subraya que "habitualmente las promociones no se testan para averiguar el grado de interés del lector antes de lanzarlas al mercado" (Santana, 2002: 334). Esto pone de manifiesto que a pesar de otorgar a la promoción de ventas una importante responsabilidad en relación a la difusión de ejemplares, su puesta en marcha no se hace bajo las directrices y pruebas que se estiman pertinentes y que llevarían a garantizar el verdadero éxito de la acción.

5 El Libro Blanco de la prensa diaria distingue entre promociones y promociones con aumento de precio y en ambos casos se aprecia una evolución al alza desde el año 2000 en lo que a la prensa en general se refiere: de 997 promociones en el año 2000 a 2.085 en 2007 y de 483 promociones con aumento de precio en el año 2000 a 1.480 en el año 2007. 
El estudio llevado a cabo por la profesora Santín Durán sobre el contenido autorreferente de la prensa sitúa a los mensajes sobre promociones de ventas entre los tres mayoritarios. La autora suscribe que de la totalidad de temas propios detectados, aquellos que han adquirido mayor peso con el paso del tiempo son los relatos informativos que versan sobre la promoción de ventas, seguidos de los que tratan la entrega de premios y el contenido de los suplementos (Santín, 2009). Las conclusiones extraídas de los estudios previos son:

- Que la promoción de ventas no generan fidelidad a largo plazo, ya que atrae a un consumidor puntual.

- Que solo un escaso porcentaje de personas que compran el diario por la promoción de ventas se convierte en lector habitual, es decir, no se consigue el objetivo de aumentar las ventas a largo plazo.

- Que el hecho de que los lectores se decanten por una u otra cabecera no depende exclusivamente de la promoción de ventas.

- Que no se suelen llevar a cabo estudios previos para asegurar la eficacia de la promoción de ventas.

- Y en relación a cómo la promoción de ventas repercute en el propio producto, que los mensajes sobre las mismas ocupan un protagonismo excesivo en el diario.

\subsection{Características de la promoción de ventas en prensa}

Con el objetivo de definir las características fundamentales de la técnica de promoción de ventas y comprobar así su correcta o incorrecta puesta en práctica por parte de los diarios analizados, resulta interesante acudir a su definición: "Conjunto de incentivos, generalmente a corto plazo, diseñados para estimular rápidamente, y/o en mayor medida, la compra de determinados productos o servicios por parte de los consumidores" (Montero, 2005: 221).

Destacamos a continuación algunos de los objetivos que persigue la promoción de ventas dirigida al consumidor final, según Rodríguez Centeno (2004: 45-46): incentivar la prueba y el conocimiento del producto; incrementar su tasa de consumo (como por ejemplo las ofertas $2 \times 1$ ); contrarrestar las acciones publicitarias y promocionales de la competencia; incentivar el conocimiento de productos complementarios (una muestra de champú con la compra de un gel); combatir la estacionalidad de ciertos artículos; liquidar artículos de stock anticuado y obtener datos de clientes para futuras campañas.

Es lógico que ante la avalancha de productos tan similares, no exista un perfil definido en la mente del lector sobre qué tipo de promoción de ventas se asocia con el diario que él adquiere habitualmente: "La competencia entre los diarios en materia promocional conlleva el lanzamiento de acciones muy parecidas que desconciertan al público hasta el punto de no discernir entre las iniciativas de cada cabecera" (Ferrán, 2008: 22). A lo expuesto se suma el argumento que cuestiona si realmente el producto promocionado guarda algún tipo de relación con la esencia del medio. Es decir, la cuestión que se cierne sobre si la promoción del artículo tiene algo que ver con el diario o si el solo hecho de verlos unidos en el kiosco puede dar lugar a cierta confusión en la mente del consumidor:

"Muchos publicistas consideran que regalar por regalar no lleva a ninguna parte. Incluso se corre el peligro de obtener un resultado contrario al esperado, ya que el lector puede llegar a plantearse la siguiente reflexión: "Si para que compre un diario me regalan un libro, o una toalla o una botella de champán, debo entender que sin regalo el editor considera que su diario no vale nada" (Montero, 2005: 224).

Deducimos que aunque el objetivo fundamental de la acción de promoción de ventas sea incrementar las ventas, la herramienta debería orientarse también a fortalecer y consolidar la retención de los que ya son asiduos lectores: "Además de incrementar la venta, los otros dos grandes objetivos de las promociones son fidelizar a nuestros lectores para que no nos abandonen y fomentar la prueba de nuestra publicación para mejorar su conocimiento entre determinados públicos cercanos, que también podrían ser fidelizados" (Montero, 2005: 224).

Entre los peligros que se derivan del uso y abuso de esta técnica encontramos:

- Que se produzca un deterioro del concepto de la publicación en la mente del lector, quien termine otorgando más valor al producto promocionado que a la propia publicación. Existe 
el peligro de que además de poner en entredicho el valor de la publicación, esta concepción se expanda también al contenido editorial.

- El siguiente contratiempo alude a que la escasa calidad del artículo perjudique la credibilidad de la publicación. El lector, cansado del producto que se rompe en un par de días o de la 'baratija' que nada tiene que ver con la fotografía del anuncio, termina por asociar esa falta de calidad a la publicación. "Según esta versión, es mejor gastarse el dinero en ofrecer más papel, más páginas y de mejor calidad, que en regalar el mejor bolígrafo" (Montero, 2005: 226).

- Existe igualmente el peligro de que la promoción de ventas acabe siendo un método menos rentable de lo que se había previsto: "Hay veces en que no se acierta con el regalo, por lo que resulta que la publicación ha realizado una operación costosa con unos pobres resultados" (Montero, 2005: 226). Y, por otro lado, puede suceder que "cuando se acierta y efectivamente se produce una subida de ventas en un número determinado, la retención de compradores que quedan para el número siguiente sea mínima (Montero, 2005: 226). Como subraya el experto, "en la práctica, los regalos de cada revista neutralizan unas a otras" (Montero, 2005: 226). Existe la posibilidad de que sea el mismo éxito de la promoción el que termine convirtiéndose en perjudicial: "Registrar un éxito superior al esperado en una campaña promocional resulta paradójicamente contraproducente para un periódico para el que la ruptura de stocks no le permite satisfacer las demandas en el plazo de entrega previsto (Ferrán, 2008: 50). La autora pone como ejemplo el caso de El Periódico de Catalunya que, ante la entrada masiva de ciento cincuenta mil pedidos de la primera pieza de una batería de cocina, se vio incapacitado para abastecer la demanda con las cien mil unidades del almacén. Esto provocó un sentimiento de desconfianza en la mente del lector.

- Por último, se mencionan las cifras de clientes falsas para los anunciantes. La promoción de ventas puede atraer a una serie de clientes movidos por el artículo promocionado que no respondan al perfil que buscan los anunciantes cuando insertan su anuncio en una determinada publicación. "Las promociones han alterado dicho mercado, haciendo que ya no sepamos muy bien qué es lo que motiva la compra de los medios impresos: el producto editorial o el regalo que lo acompaña" (Álvarez, 2006).

Por definición, la promoción de ventas constituye un abanico de acciones de refuerzo caracterizadas por el plazo limitado, ya que, de lo contrario, pierden eficacia. Hemos comprobado que su objetivo principal es fomentar la adquisición del producto al que acompañan, a través del incentivo, no la adquisición del incentivo. Por lo tanto, las características que debe cumplir la estrategia de promoción de ventas son: el corto plazo, estimular la compra, fidelizar, contrarrestar las acciones publicitarias de la competencia, dar salida al stock y respetar la sintonía con el producto al que acompañan.

\section{Los diarios objeto de estudio}

\subsection{Málaga \\ 4.1.1. Diario Sur}

\begin{tabular}{|l|l|}
\hline Año de fundación y director actual & 1937, José Luis Romero Silva \\
\hline Ubicación & Avenida Doctor Marañón, 48 \\
& C.P : 29009. Málaga \\
\hline Ámbito de distribución & $\begin{array}{l}\text { Málaga capital y provincia. Se envían } \\
\text { ejemplares a algunos kioscos de Sevilla, } \\
\\
\text { Granada y Córdoba }\end{array}$ \\
\hline Periodicidad & Matutino y diario \\
\hline Ediciones & Última edición (Málaga capital), Marbella \\
& - Estepona, Campo de Gibraltar y Ceuta, \\
& Melilla. Además de ediciones Sur en Inglés \\
& y Alemán \\
\hline Pertenencia a grupo empresarial & Vocento \\
\hline Página web & www.diariosur.es \\
\hline
\end{tabular}




\begin{tabular}{|c|c|}
\hline Promedio tirada diaria (OJD, 2010) & 34.929 \\
\hline Promedio difusión diaria (OJD, 2010) & 28.809 \\
\hline Lectores diarios (EGM, 2010) & 164.000 \\
\hline Perfil de la audiencia & $\begin{array}{l}\text { Principalmente hombres urbanos, más de } \\
\text { la mitad con menos de } 50 \text { años, elevada } \\
\text { formación y buen estatus social }\end{array}$ \\
\hline Precio & $\begin{array}{l}\text { 1,20€ entre semana, } 2,20 € \text { los domingos y } \\
2,50 € \text { ( con revista Hoy Corazón) (puede } \\
\text { aumentar dependiendo de si le } \\
\text { acompaña un producto promocional) }\end{array}$ \\
\hline
\end{tabular}

4.1.2. La Opinión de Málaga

\begin{tabular}{|l|l|}
\hline Año de fundación y director actual & 1999, Juan de Mellado \\
\hline Ubicación & C/ Granada 42. C.P: 29105. Málaga \\
\hline Ámbito de distribución & Málaga capital y provincia \\
\hline Periodicidad & Matutino y diario \\
\hline Ediciones & Málaga capital y provincia \\
\hline Pertenencia a grupo empresarial & Prensa Ibérica \\
\hline Página web & www.laopiniondemalaga.es \\
\hline Promedio tirada diaria (OJD, 2010) & 7.347 \\
\hline Promedio difusión diaria (OJD, 2010) & 5.660 \\
\hline Lectores diarios (EGM, 2010) & 23.400 \\
\hline Perfil de la audiencia & $\begin{array}{l}\text { Principalmente hombres de mediana } \\
\text { edad, quienes residen en núcleos urbanos } \\
\text { de clase media -alta y presentan un buen } \\
\text { nivel de estudios }\end{array}$ \\
\hline Precio & $\begin{array}{l}1,20 € \text { entre semana, 1,50 } € \text { los domingos } \\
\text { (puede aumentar dependiendo de si le } \\
\text { acompaña un producto promocional) }\end{array}$ \\
\hline
\end{tabular}

\subsection{Alicante}

4.2.1. Diario Información

\begin{tabular}{|l|l|}
\hline Año de fundación y director actual & 1941, Juan R. Gil \\
\hline Ubicación & $\begin{array}{l}\text { Avenida Doctor Rico, 17. C.P.: } 03005 . \\
\text { Alicante }\end{array}$ \\
\hline Ámbito de distribución & Provincia de Alicante \\
\hline Periodicidad & Matutino y diario \\
\hline Ediciones & $\begin{array}{l}\text { Alicante, Elche, Orihuela-Vega Baja, Las } \\
\text { Marinas, Alcoy y Elda }\end{array}$ \\
\hline Pertenencia a grupo empresarial & Prensa lbérica \\
\hline Página web & www.diarioinformacion.com \\
\hline Promedio tirada diaria (OJD, 2010) & 33.316 \\
\hline Promedio difusión diaria (OJD, 2010) & 26.779 \\
\hline Lectores diarios (EGM, 2010) & 232.000 \\
\hline Perfil de la audiencia & $\begin{array}{l}\text { Principalmente hombre, entre 35 y } 60 \text { años, } \\
\text { con estudios y de clase social Media-alta y } \\
\text { Alta, por encima de la media de la } \\
\text { provincia }\end{array}$ \\
\hline Precio & $\begin{array}{l}1,10 € \text { entre semana, } 2 € \text { domingo (puede } \\
\text { aumentar dependiendo de si le } \\
\text { acompaña un producto promocional) }\end{array}$ \\
\hline
\end{tabular}




\subsubsection{La Verdad}

\begin{tabular}{|c|c|}
\hline Año de fundación y director actual & 1903, Alberto Aguirre de Cárcer \\
\hline Ubicación & $\begin{array}{l}\text { Camino Viejo de Monteagudo, S/N. C.P.: } \\
\text { 30007. Murcia }\end{array}$ \\
\hline Ámbito de distribución & Murcia, Alicante y Albacete \\
\hline Periodicidad & Matutino y diario \\
\hline Ediciones & $\begin{array}{l}\text { Murcia (Murcia, Cartagena, Lorca y } \\
\text { comarcas); Alicante (Alicante, Elche, } \\
\text { Orihuela-Vega Baja y Provincia) y } \\
\text { Albacete }\end{array}$ \\
\hline Pertenencia a grupo empresarial & Vocento \\
\hline Página web & http://www.laverdad.es/ \\
\hline Promedio tirada diaria (OJD, 2010) & 40.478 \\
\hline Promedio difusión diaria (OJD, 2010) & 33.463 \\
\hline Lectores diarios (EGM, 2010) & 235.000 \\
\hline Perfil de la audiencia & $\begin{array}{l}\text { El lector de La Verdad es principalmente } \\
\text { masculino, con edades comprendidas } \\
\text { entre los } 35 \text { y los } 65 \text { años, de clase social } \\
\text { alta o media. }\end{array}$ \\
\hline Precio & $\begin{array}{l}\text { 1,10€, hasta } 2 € \text { en domingo (puede } \\
\text { aumentar dependiendo de si le } \\
\text { acompaña un producto promocional) }\end{array}$ \\
\hline
\end{tabular}

\section{Metodología}

La metodología utilizada en la investigación es de carácter triangular (Wimmer y Dominick, 1996: 50-51), puesto que combina técnicas cualitativas (entrevista) y cuantitativas (análisis de contenido) para llevar a cabo el análisis de las promociones de ventas de los diarios desde diferentes ángulos de estudio. El trabajo ofrece una radiografía real del uso que los diarios hacen de esta técnica, con el objetivo final de apuntar mejoras.

El grueso de la investigación consiste en el análisis de todas las promociones de ventas realizadas por las distintas cabeceras del estudio en el año 2010: los dos diarios locales malagueños, Diario Sur y La Opinión de Málaga y las cabeceras alicantinas: Diario Información y La Verdad. El estudio se centra en las cabeceras locales de dos provincias de tamaño mediano, que no son capital de Comunidad Autónoma y que, además, comparten por pares el mismo grupo de comunicación: Vocento (Diario Sur y La Verdad) y Prensa Ibérica (La Opinión de Málaga y Diario Información), lo que permite establecer comparativas en su modo de actuar. Se establece una serie de ítems que clasifican la muestra según tipo de producto, fecha de inicio y fin de la promoción de ventas, periodicidad y número total de promociones puestas en marcha. Todo ello de acuerdo a las características que debe cumplir la técnica de acuerdo al marco teórico descrito.

Para determinar el grado de relación de la promoción de ventas con el diario y de acuerdo a las aportaciones de Montero6, se establecen tres niveles de relación del producto promocionado con el perfil de la publicación: periódico local de pago con contenidos generalistas.

1. Producto editorial /Educación, Música y cine Todos ellos constituyen productos que, si no fomentan directamente la lectura, están englobados dentro de lo que tradicionalmente se entiende como ámbito cultural, en contraposición a los

6 "En general, son muy bien valorados aquellos regalos que suponen una extensión del contenido de la publicación o bien están muy cercanos al ámbito o la cultura de la misma. Constituyen este tipo de regalos aquellos de papel (libros u otras publicaciones) o bien material diverso de ocio (películas, DVD, música...)" (2005: 225). Y añade: "La mayor duda surge con las promociones basadas en regalos que no tienen una relación directa con la publicación. Aunque es una práctica extendida en publicaciones de todo tipo, son especialmente intensas en revistas femeninas, de decoración y moda" (Montero, 2005: 227) 
artículos más relacionados con el puro entretenimiento (Rodríguez Ferrándiz, 2010). Consideramos que ofrecer a los lectores películas, libros y colecciones de música contribuye a despertar o aumentar su interés por estos sectores, de manera que se propicia que se conviertan en ávidos consumidores de las noticias y textos que a estos ámbitos culturales dediquemos y, por ende, se despierte su interés en seguir adquiriendo el diario de una forma más o menos habitual.

2. Idiosincrasia local

Este nivel comprende aquellas promociones de ventas que, aunque no fomentan directamente el hábito de la lectura de nuestro público, sí presentan una relación coherente con la publicación por disponer de otras características, como puede ser su relación con la idiosincrasia local. Entre los artículos que encontramos en este nivel destacan aquellos que promocionan determinados parajes y localidades de la provincia en la que se distribuye el diario o que fomentan el deporte regional.

3. Resto

En este nivel se agrupan los productos cuya naturaleza está más alejada de la esencia del diario.

El análisis descrito se completa con los resultados obtenidos de la entrevista a los responsables de marketing de las cuatro cabeceras: Miguel Llobel (Diario Información), Ma Carmen Valentín (La Verdad), Joaquín Cestino (Diario Sur) y Raúl Rico (gerente adjunto de La Opinión de Málaga, la cabecera no cuenta con la figura de director de Marketing). La estructura del cuestionario era flexible, a partir de un esquema preestablecido con los temas que interesaban para dar respuesta a los objetivos de la investigación (Rubin y Rubin, 2005; King y Horrocks, 2010).

La investigación se amplía con el estudio de los departamentos de marketing de otros sectores ajenos a la prensa, pero donde el marketing juega un papel fundamental. De esta manera, tomamos contacto con empresas de otro sectores tales como: Mercedes Benz, El Corte Inglés Andalucía Oriental; Nespresso, Caja Rural del Sur e Isoft, con el objetivo de comparar sus estrategias de promoción de ventas con las propias de las cabeceras locales.

\section{Resultados}

A continuación se presentan los resultados del análisis del conjunto de promociones de ventas puestas en marcha por los diarios que comprenden la muestra y se complementan con las impresiones obtenidas en las entrevistas, ofreciendo una explicación más profunda de los datos.

\subsection{Número y duración de las promociones de ventas analizadas}

De las cuatro cabeceras analizadas, aquella que otorga mayor protagonismo a la promoción de ventas que acompaña al periódico es el Diario Sur (77), seguido del Diario Información (66). Ambos periódicos son los líderes en venta y difusión ${ }^{7}$ en sus respectivos territorios, lo que establece a primera vista una relación entre número de lectores y total de promociones de ventas. No obstante, cuando tenemos en cuenta los datos arrojados por La Verdad (59 promociones) la relación proporcional entre promociones de ventas y lectores se desvirtúa, ya que a pesar de tratarse del segundo diario de la provincia (en cuanto a tirada y difusión) también presenta un número de promociones elevado. Es decir, en la puesta en marcha de esta estrategia también intervienen otros factores aparte del que persigue aumentar el número de ventas, como es el de contrarrestar las acciones de la competencia, como veremos más adelante.

La Opinión de Málaga es de los cuatro rotativos analizados aquel que menos promociones de ventas registra (36), de la misma manera que la media de duración de las mismas también es la más baja (20 días), junto con el diario La Verdad (21). Por su parte, el Diario Sur presenta una media de duración de sus promociones de ventas superior a los 40 días, es decir, los productos que acompañan al ejemplar permanecen en almanaque mucho más de un mes. Este dato pone de manifiesto hasta qué punto se desvirtúa el concepto inicial de la técnica entendida como una acción a corto plazo.

Respecto a las promociones de ventas con mayor y menor duración a lo largo del ejercicio se observa que en los cuatro casos aquellas basadas en utensilios de cocina (vajilla, cuchillos,

$7 \quad$ Como se puede comprobar en las fichas adjuntadas en el epígrafe número 4. 
recipientes...) cuentan con un protagonismo notable, ya sea para ocupar los puestos de mayor duración, como los de menor. También se percibe que entre los productos con mayor duración en el calendario aparecen, lógicamente, aquellos que se pueden ofrecer de forma fraccionada: colecciones de libros y de música y de nuevo piezas de cocina. Entre los que poseen menor duración destacan aquellos que se suelen ofrecer a través de cartillas o recortando cupones, sobre todo en el caso de los productos de mayor coste, como son los del ámbito de la informática (mini cadena, impresora y disco duro). Pero también los que tienen un coste mínimo, casos en los que el periodo de la promoción de ventas es de uno, dos o tres días (póster de Navidad, pulseras o láminas de algún pintor local).

\begin{tabular}{|c|c|c|c|c|c|c|c|}
\hline \multicolumn{2}{|l|}{ Información } & \multicolumn{2}{|l|}{ La Verdad } & \multicolumn{2}{|l|}{ Diario Sur } & \multicolumn{2}{|c|}{ La Opinión de Málaga } \\
\hline \multicolumn{8}{|c|}{ Número de promociones, 2010} \\
\hline \multicolumn{2}{|l|}{66} & \multicolumn{2}{|l|}{59} & \multicolumn{2}{|l|}{77} & \multicolumn{2}{|l|}{36} \\
\hline \multicolumn{8}{|c|}{ Media de duración de las promociones, 2010 (días) } \\
\hline \multicolumn{2}{|l|}{23} & \multicolumn{2}{|l|}{21} & 46 & \multicolumn{2}{|r|}{20} & \\
\hline \multicolumn{8}{|c|}{ Ranking de promociones con mayor duración, 2010 (días) } \\
\hline Libros II GM & \multicolumn{2}{|c|}{211 Rosario } & \multicolumn{3}{|c|}{ 307Casa muñeca } & 376Cuchillos jap. & 302 \\
\hline Sartenes & \multicolumn{2}{|c|}{ 138Portátil } & \multicolumn{2}{|c|}{ 261Música clásica } & \multicolumn{2}{|c|}{ 273Películas } & 140 \\
\hline Cuentos & 84 & Recipientes & \multicolumn{2}{|c|}{ 245Cuerpo Humano } & \multicolumn{2}{|c|}{ 230Cubertería } & 123 \\
\hline Vajilla & 84 & Cómics & \multicolumn{2}{|c|}{ 202DVD Oscars } & \multicolumn{2}{|c|}{ 224Cuentos } & 84 \\
\hline Pulsera & 79 & Llam. Ángeles8 & 88 & Juguetes clas. & & 8Cine De Niro & 77 \\
\hline \multicolumn{8}{|c|}{ Ranking de promociones con menor duración, 2010 (días) } \\
\hline Cám. Hello kitty & 4 & Tarros cocina & 5 & Post. Navidad & 1 & Tarros & 5 \\
\hline Album Panini & 6 & Directores cine & 7 & Pulsera pie & 2 & Batería cocina & 6 \\
\hline Mini Cadena & 8 & Dvd Humphrey & 7 & Pintor malagueño & 3 & Botella Nestea & 7 \\
\hline Colgante Navidad & 10 & El cuerpo hum. & 9 & Impresora & 5 & Set barbacoa & 14 \\
\hline Disco Duro & 11 & Set ensaladas & 11 & 3 DVD+TDT & 6 & Camiseta toros & 16 \\
\hline
\end{tabular}

Tabla 1. Total de promociones, media de duración y ranking

Fuente: elaboración propia a partir de datos facilitados por las propias cabeceras

\subsection{Relación entre el tipo de producto promocionado y perfil de la publicación}

La figura número 1 demuestra que la mayor parte de las promociones de ventas lanzadas en el año 2010 por las cabeceras del estudio son de nivel 3, es decir, las que se alejan más de la naturaleza del producto. Si analizamos el cuadro de promociones de ventas de los distintos diarios en 2010 llegamos a la conclusión de que no se persigue la creación de identidad propia. Igual se lanza una pulsera, que unas sartenes, o un disco duro. Da la sensación de que 'todo vale' con tal de vender.

Las dos cabeceras principales en Málaga y Alicante: Diario Sur y Diario Información, proyectaron un gran número de promociones de ventas relacionadas con la idiosincrasia local, sobre todo el Diario Sur. Esto forma parte de su estrategia de producto, como bien explicó su director de Marketing durante la entrevista. La cabecera pretende convertirse en el periódico de Málaga. De las 77 promociones realizadas en 2010, 20 fueron de temática malagueña. 


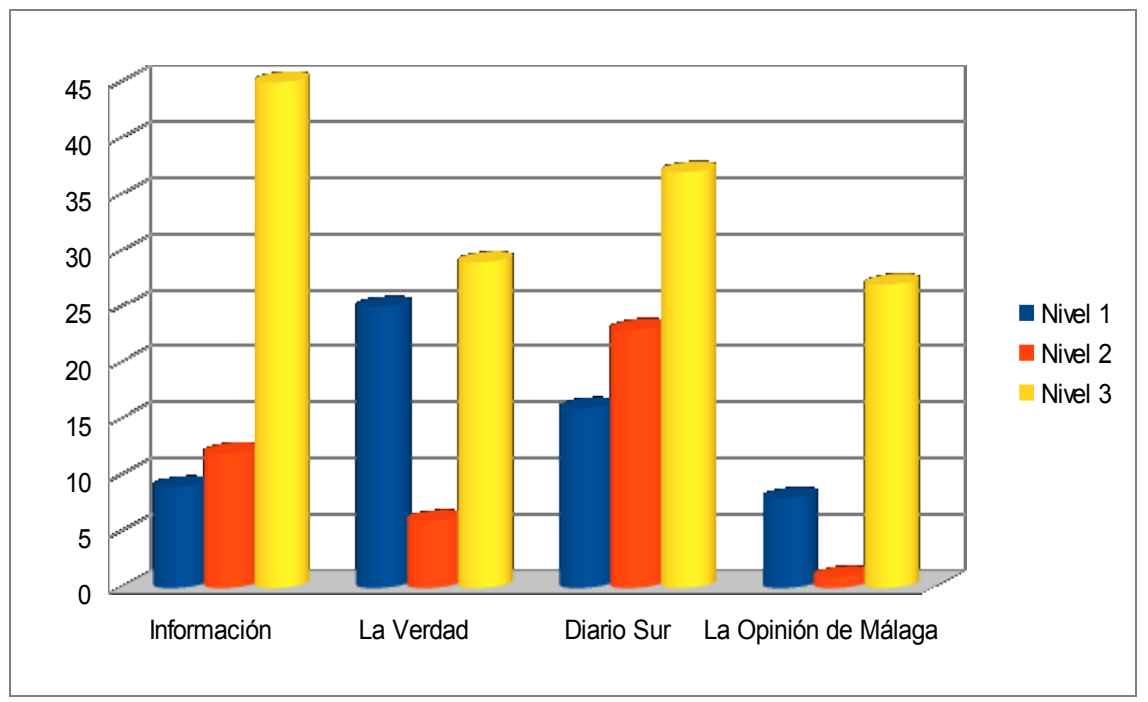

Figura 1. Promociones clasificadas por niveles de relación con el diario como producto Fuente: elaboración propia a partir de datos facilitados por las propias cabeceras

\subsection{La relación entre las promociones de ventas y la tirada y difusión}

En la figura número 2, que compara las dos cabeceras principales de Alicante, se observa una ligera superioridad en número de promociones por parte del Diario Información a lo largo de la mayoría de meses. Esta diferencia coincide con las opiniones de los directores: mientras Miguel Llobel (Diario Información) ve en la estrategia una herramienta indispensable para atraer lectores, $M^{a}$ Carmen Valentín (La Verdad) explica que al tratarse de una técnica practicada por la mayoría de periódicos, la cabecera se ve obligada a utilizarla para no quedar rezagada frente a sus competidores.

Resulta lógico por lo tanto que el segundo diario en número de lectores en Alicante registre un total de promociones de venta algo menor, puesto que utiliza la técnica como una forma de contrarrestar las acciones de la competencia. Corrobora lo expuesto el hecho de que los meses de febrero, abril, septiembre y noviembre sean aquellos en los que el Diario Información registra menos promociones y ocurra todo lo contrario en el caso de La Verdad, que parece aprovechar este periodo en el que el competidor 'se relaja', para incrementar su estrategia en busca de un aumento de la difusión.

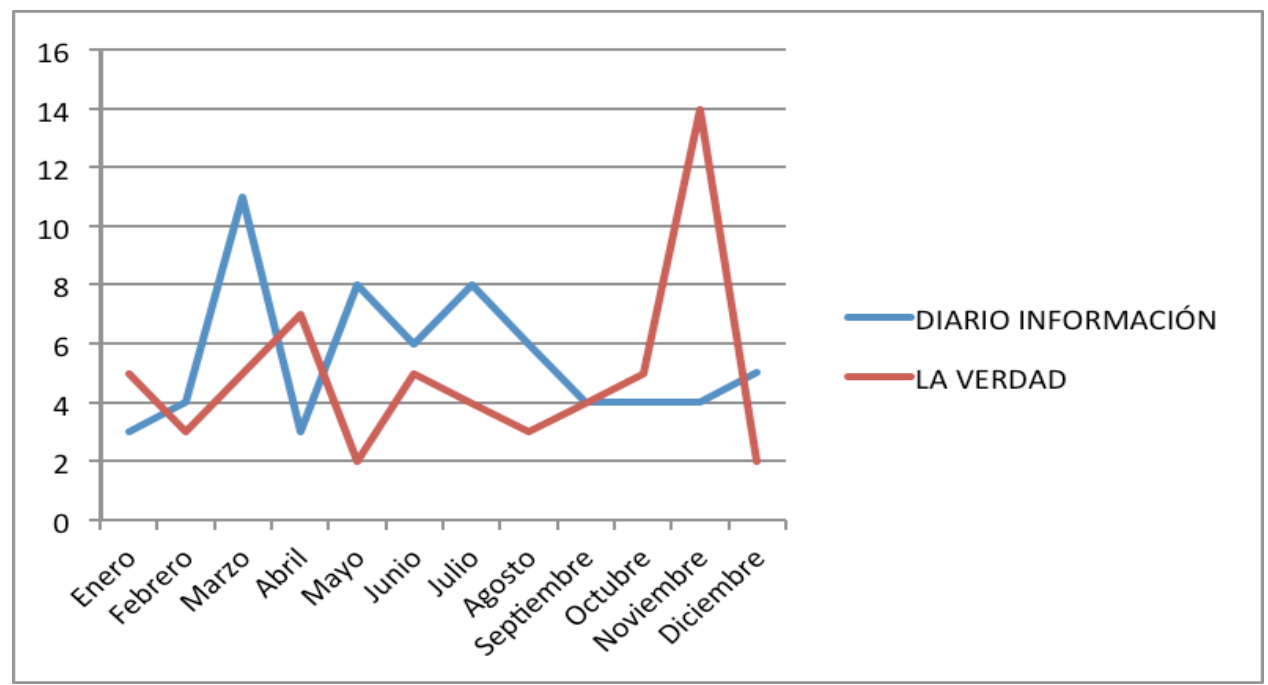

Figura 2. Comparativa Información y La Verdad: frecuencia del total de promociones Fuente: elaboración propia a partir de datos facilitados por las propias cabeceras 
En la comparativa entre los rotativos malagueños también se intuye una estrategia para hacer frente a la competencia, ya que de nuevo los picos tienden a contraponerse. Por ejemplo, en el mes de abril descienden las promociones de ventas en el Diario Sur, mientras que en La Opinión de Málaga aumentan ligeramente y lo mismo ocurre, todavía de forma más acusada, en el mes de mayo. Aunque en esta ocasión a partir del segundo semestre la evolución de las promociones de ventas en ambas cabeceras tiende a equipararse.

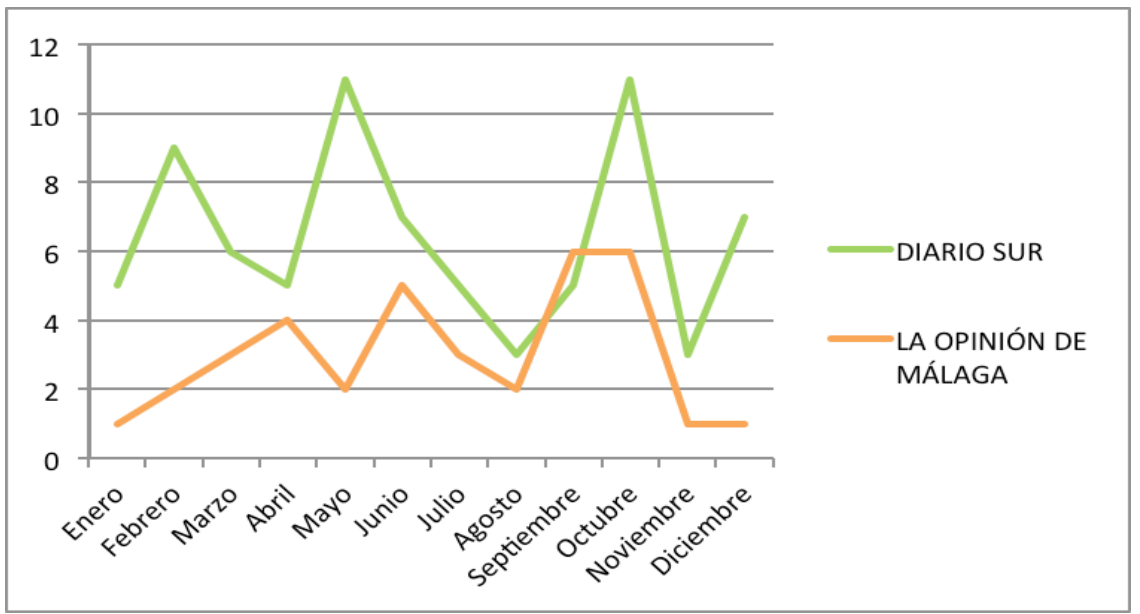

Figura 3. Comparativa D. Sur y La Op. de Málaga: frecuencia del total de promociones

Fuente: elaboración propia a partir de datos facilitados por las propias cabeceras

Al tener en cuenta los datos facilitados por OJD sobre tirada y difusión se observa en la tabla número 2 que no existe una relación clara entre estas dos variables y el número de promociones de ventas según el mes. Si atendemos a las cabeceras alicantinas, el mes con un mayor número de promociones de ventas en el Diario Información es marzo, donde sí se aprecia una cifra también alta de tirada y difusión, pero si observamos el segundo mes con mayor número de promociones de ventas en este mismo diario (julio), la relación ya no se cumple, puesto que las cifras de tirada y difusión son inferiores a las de otros meses con menos promociones de ventas. En el caso del diario La Verdad la relación tampoco es clara, ya que de nuevo los meses en los que se han contabilizado un mayor número de promociones de ventas (noviembre y abril) no son aquellos que destacan en cuanto a tirada y difusión (febrero y marzo).

Si atendemos a los diarios malagueños la relación tampoco se cumple: mientras los meses con mayor número de promociones en el Diario Sur son mayo y octubre, aquellos con mayor tirada y difusión son marzo y abril. Y si nos centramos en el mes de enero en el diario La Opinión de Málaga, observamos que tan solo registra una promoción, mientras que es uno de los meses con mayor tirada y difusión (solo por debajo de octubre).

Asimismo, el mayor número de promociones de ventas lanzadas a lo largo de un mes concreto tampoco parece generar fidelización de lectores, ya que si así fuera la audiencia se mantendría o incluso se incrementaría durante el mes siguiente y vemos que no es el caso. 


\begin{tabular}{|l|l|l|l|l|l|l|l|l|l|l|l|l|}
\hline & \multicolumn{4}{|l|}{ D. Información } & \multicolumn{2}{l|}{ La Verdad } & \multicolumn{2}{l|}{ Diario Sur } & \multicolumn{2}{l|}{ Op. de Málaga } \\
\cline { 2 - 14 } & Prom & Tirada & Difusión & Prom & Tirada & Difusión & Prom & Tirada & Difusión & Prom & Tirada & Difusión \\
\hline ene & 3 & 31.500 & 26.234 & 5 & 26.234 & 31.728 & 5 & 33.084 & 21.248 & 1 & 7.922 & 3.061 \\
\hline feb & 4 & 34.772 & 29.368 & 3 & 29.368 & 35.431 & 9 & 34.522 & 22.070 & 2 & 7.205 & 2.864 \\
\hline mar & 11 & 36.416 & 30.899 & 4 & 30.899 & 34.383 & 6 & 36.039 & 22.390 & 3 & 6.763 & 2.665 \\
\hline abr & 3 & 34.776 & 28.938 & 7 & 28.938 & 32.648 & 5 & 35.822 & 21.845 & 4 & 7.550 & 2.073 \\
\hline may & 8 & 32.311 & 27.445 & 2 & 27.445 & 33.980 & 11 & 32.473 & 21.835 & 2 & 7.354 & 2.859 \\
\hline jun & 6 & 32.183 & 26.717 & 5 & 26.717 & 31.791 & 7 & 31.297 & 21.070 & 5 & 7.246 & 2.865 \\
\hline jul & 8 & 29.790 & 24.314 & 4 & 24.314 & 31.999 & 5 & 31.417 & 21.888 & 3 & 5.700 & 2.635 \\
\hline ago & 6 & 30.106 & 24.587 & 3 & 24.587 & 31.888 & 3 & 33.821 & 23.340 & 2 & 6.095 & 2.826 \\
\hline sep & 4 & 32.004 & 26.659 & 4 & 26.659 & 33.288 & 5 & 31.744 & 20.441 & 6 & 7.682 & 2.825 \\
\hline oct & 4 & 33.053 & 27.587 & 5 & 27.587 & 32.677 & 11 & 33.211 & 20.019 & 6 & 8.029 & 3.116 \\
\hline nov & 4 & 31.835 & 26.629 & 14 & 26.629 & 30.746 & 3 & 29.790 & 19.142 & 1 & 6.891 & 2.582 \\
\hline dic & 5 & 31.758 & 25.212 & 2 & 25.212 & 29.539 & 7 & 31.227 & 20.716 & 1 & 6.568 & 2.457 \\
\hline
\end{tabular}

Tabla 2. Relación entre promociones de ventas, tirada y difusión, año 2010

Fuente: elaboración propia y con datos proporcionados por OJD

\section{La estrategia de la promoción de ventas en otros sectores: comparativa}

La diferencia fundamental entre la forma de planificar las promociones de ventas en los departamentos de Marketing de las empresas consultadas y los de las cabeceras analizadas se refleja en la respuesta al siguiente interrogante: ¿ Con cuánto tiempo se planifican las promociones? En el caso de los diarios estudiados, hemos comprobado que la respuesta que nos daban era, como ya apuntábamos, extremadamente cortoplacista, algo que no coincide con el comportamiento de las empresas de los otros sectores: Nespresso planifica su estrategia de promoción de ventas con 6 meses de adelanto en el caso de las promociones que provienen de la central y con 3 meses para las de ámbito nacional; El Corte Inglés Andalucía Oriental se toma 3 semanas para planear sus promociones de venta locales; Mercedes Benz planifica anualmente; Caja Rural lo hace con 6 meses de adelanto e Isoft de forma semestral/ anual.

Estos datos destapan no solo la escasez de tiempo con que planifican las promociones de ventas los diarios locales, sino también cierta falta de criterio. Por ejemplo, por todos son conocidas las campañas estacionales que lleva a cabo El Corte Inglés, casi institucionalizadas: "La vuelta al cole" en septiembre con sus 'cheques' y 'corticoles'; "Los 8 días de Oro", "La Semana Fantástica"... Nespresso también cuenta con dos fechas claves para concentrar la actividad promocional: una en Navidad y la otra en primavera, donde se regalan cheques-descuento por la compra de la máquina de café. Asimismo, los bancos refuerzan su actividad cuando llega la época de octubre y hasta final de año (con los Planes de Pensiones); y los concesionarios de coches lanzan promociones para compra/reparación o revisión de los vehículos los meses antes de empezar el periodo vacacional de verano (el llamado Plan Renove).

Es así cómo los potenciales clientes de un producto se aprovechan de las ofertas estacionales, previsibles, de tal manera que la empresa se asegura unas ventas y evita generar un continuo 'bombardeo' publicitario a sus clientes. Mientras, el sector de la prensa local se muestra reticente a racionalizar su estrategia promocional, con la consecuente pérdida de eficacia.

\section{Conclusiones}

De las cuatro cabeceras analizadas aquellas que otorgan mayor protagonismo a la promoción de ventas son las dos líderes en su zona en cuanto a tirada y difusión: el Diario Sur y el Diario Información. Sin embargo, no queda del todo demostrada la existencia de una relación entre compradores y promociones, ya que el diario La Verdad de Alicante casi iguala a su competidor en número de promociones de ventas y se encuentra muy por debajo en cuanto a número de ejemplares impresos y vendidos. Además, los datos proporcionados por estudios profesionales indican que, en términos generales, mientras que las promociones de ventas han aumentado, las 
ventas y los ingresos de las cabeceras españolas han disminuido. En términos generales, un mayor número de promociones de ventas en un mes determinado, no es garantía de que la cifra de tirada y difusión aumente en dicho mes ni de que se consiga fidelizar al lector. La mayoría de productos promocionados por los cuatro rotativos está alejada de la esencia del diario. Se prima la promoción de ventas de artículos relacionados con el mundo de la moda, la cocina o la decoración, en lugar de apostar en primer lugar por aquellos productos más relacionados con el mundo de la cultura (libros, cine, música...). Sí se lanzan promociones de ventas de artículos de índole cultural, pero su proporción respecto al total es menor. Por otra parte, las cabeceras sí sacan partido a su carácter local y ofrecen una buena parte de productos relacionados con la idiosincrasia de la zona.

De las opiniones recabadas a través de las entrevistas a los responsables de marketing de sendos diarios, se extrae la conclusión de que cuando los periódicos ponen en marcha sus estrategias de promoción de ventas persiguen dos objetivos fundamentales: aumentar las ventas y contrarrestar las acciones de la competencia, pero se intuye que olvidan otros importantes. Por ejemplo, el que apuesta por la fidelización del lector, ya que las estrategias no parecen estar diseñadas bajo una línea coherente en cuanto a tipo de artículos y en muchas ocasiones se superponen y generan saturación. Es decir, la estrategia puesta en marcha por los diarios carece de planificación, mientras se ha comprobado en la comparativa con las acciones llevadas a cabo por empresas de otros sectores que sí existen otras formas planificadas y eficaces de diseñar la estrategia de promoción de ventas.

\section{Bibliografía}

ASOCIACIÓN DE EDITORES DE DIARIOS ESPAÑOLES. Libro blanco de la prensa diaria. AEDE, 2012. ÁlVAREZ SÁNCEHZ-ARJONA, P. "Lo que se vende en el quiosco". Tendencias' 06. Medios de Comunicación. El año de la televisión. Fundación Telefónica, 2006, 55. Disponible en: http://www.infoamerica.org/TENDENCIAS/tendencias/tendencias06/indice01.htm Fecha de consulta: 15 de abril 2010.

AIMC. Estudio General de Medios. Comunidades y provincias. 3er. Acumulado 2010

Febrero/Diciembre 2010

CRESPO DE LARA , Pedro. La empresa periodística en vivo. Del autoritarismo a la democracia. Ariel Comunicación, Barcelona, 1993.

FERRÁN MORGADO, A. Las promociones gratuitas y de venta opcional en la prensa. El caso de El Periódico de Catalunya y ADN. Proyecto fin de carrera. Universitat Abat Oliva CEU. Facultat de Ciències Socials. 2008, 17. Disponible en: http://www.recercat.net/bitstream/2072/9131/2/TFCFERRAN-2008(2).pdf Fecha de consulta: 7 de abril 2010.

LARRAÑAGA RUBIO, J. Análisis económico de la evolución de las audiencias de los medios tradicionales e impacto de Internet en su consumo. Área Abierta, 21, 2008. Disponible en: http://revistas.ucm.es/index.php/ARAB/issue/archive. Fecha de consulta: 15 de enero de 2021. LOVELOCK, C.H. Classifying Services to Gain Strategic Marketing Insights. Journal of Marketing, 47, 1983, 9-20.

LÓPEZ, Manuel. Nuevas competencies para la prensa del siglo XXI. Paidós Ibérica. Barcelona, 2004. KING N. y HORROCKS C. Interviews in Qualitative Research. Sage Publications. Thousand Oaks (California), 2010.

MARTíNEZ FERNÁNDEZ, V.A; JUANATEY BOGA, O. y OROSA GONZÁLEZ J.J.: "El impacto sobre la fidelidad y lealtad a las marcas de las promociones de ventas: análisis del mercado de la prensa diaria en España". En (Eds.) Asociación Española de Dirección y Economía de la Empresa (AEDEM). El comportamiento de la empresa ante entornos dinámicos: XIX Congreso anual y XV Congreso Hispano Francés de AEDEM. Vitoria, Vol. 2, 2007, 3-23. Disponible en: http://dialnet.unirioja.es/servlet/libro? codigo=275383 Fecha de consulta: 15 de febrero de 2010. MONTERO RODRÍGUEZ, F.: Marketing de periódicos y revistas. Madrid, Pirámide, 2005, 221-226. OJD. Oficina de la Justificación de la Difusión. 2010. Disponible en: http://www.ojd.es/. Fecha de consulta: 15 de enero de 2012.

-. Oficina de la Justificación de la Difusión. 2011 . Disponible en: http://www.ojd.es/: 15 de enero de 2012. 
RODRÍGUEZ CENTENO, J.C. "La publicidad como herramienta de las distintas modalidades de comunicación persuasiva". Global Media Journal. Vol. 1. Núm. 001, Instituto Tecnológico y de Estudios Superiores de Monterrey, 2004, 45-46. Disponible en

http://redalyc.vaemex.mx/redalyc/src/inicio/ArtPdfRed.jsp?iCve=68710102 Fecha de consulta: 12 de junio 2010

RODRÍGUEZ FERRÁNDIZ, R. "Cultura y Ocio". Artículo publicado en el Diario Información del miércoles 30 de junio de 2010, Suplemento Arte y Letras., 2010, 1-3.

RODRÍGUEZ INIESTA, V. "SUscriptores y suscripciones periodísticas en la España de principios del siglo XX. Apuntes desde una perspectiva asturiana". Hispania. Revista Española de Historia. Vol. LXVIII, núm. 230, septiembre-diciembre, 2008, 761-786. Disponible en:

http://hispania.revistas.csic.es/index.php/hispania/article/viewFile/93/95. Fecha de consulta: 12 de junio 2010.

RUBIN, H. y RUBIN I. Qualitative Interviewing: The Art of Hearing Data. 2005.

SANTANA LÓPEZ, E. Las promociones publicitarias en la prensa. Evolución y análisis sistemático de las promociones realizadas entre los años 1990-1998 en la prensa de información general de Cataluña. Tesis Doctoral Universidad Autónoma de Barcelona. Departamento de Comunicación Audiovisual y Publicidad, 2003, 42. Disponible en: http://www.tesisenxarxa.net/TDX-1030103-164857. Fecha de consulta: 12 de mayo 2010.

SANTÍN DURÁN, M.: La autorreferencia en la prensa. La cobertura informativa de los acontecimientos propios. Madrid, Dikinson, 2009, 51.

- "El protagonismo de los medios en los diarios: el problema de la autorreferencia". Global Media Journal, 4, 7, 2007. Disponible en: http://gmje.mty.itesm.mx/santin.html Fecha de consulta: mayo 2010.

WIMMER, R.D, DOMINICK, J.R. La investigación científica de los medios de comunicación. Una introducción a sus métodos. Bosch Comunicación, Barcelona, 1996, 50-51. 